\title{
Da teoria da degeneração de Morel à classificação das doenças mentais de Kraepelin
}

\author{
From Morel's degeneration theory to \\ Kraepelin's classification of mental illness
}

\author{
Fernanda Rebelo \\ Professora do Bacharelado Interdisciplinar em Saúde/Universidade Federal da Bahia. \\ feferebelo@yahoo.com.br
}

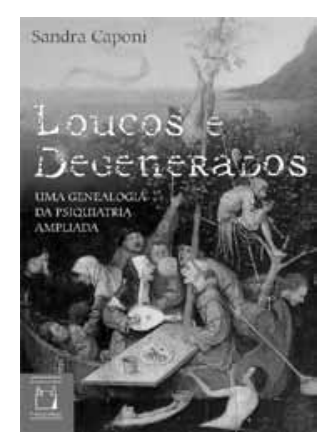

CAPONI, Sandra. Loucos e degenerados: uma genealogia da psiquiatria ampliada. Rio de Janeiro: Editora Fiocruz, 2012. 210p.
P ensar todos os conflitos e dificuldades em termos médicos é tendência nas sociedades modernas que vem sendo reforçada pela psiquiatria. Em loucos e degenerados: uma genealogia da psiquiatria ampliada, Sandra Caponi, filósofa com vasta experiência no campo da epistemologia e história das ciências da saúde, mostra como a recente multiplicação dos diagnósticos de depressão, transtornos de ansiedade ou de deficit de atenção e hiperatividade (TDH), com a promessa da melhora dos sintomas por meio da terapêutica com psicofármacos, faz parte de um conjunto de premissas articuladas historicamente. É a partir dessa tendência contemporânea, que naturaliza, considera evidente e eficaz o uso de medicamentos para dar conta de problemas do cotidiano, que a autora traça sua linha de reflexão.

Sandra Caponi toma como ponto de partida os cursos ministrados por Michel Foucault (2000a), no Collège de France, em 1975 e 1976. Foi nesses cursos que Foucault se propôs a analisar como um dispositivo de poder pode ser produtor de certo número de enunciados e de discursos, assim como de modos de representação. Diferente de sua fase anterior, conhecida como arqueológica, de 1961 a $1969^{1}$, quando o autor se dedicou às questões da produção de saber, do encerramento asilar e da violência, a partir de 1974 sua preocupação estava em compreender de que modo se estabelecem e circulam as relações de poder dentro desse campo médico que é a psiquiatria. Nessa segunda fase de cursos, publicados como livro na França, em 2003, sob o título O poder psiquiátrico, Foucault (2006b) trata da questão dos 'poderes', preocupação própria de seus estudos genealógicos. ${ }^{2}$

Assim, Loucos e degenerados possui uma clara proposta de, a partir da história da psiquiatria, pensar de outro modo as questões ligadas à medicalização na sociedade contemporânea. O objetivo está em analisar em que momento, em razão de quais estratégias teórico- 
epistemológicas e de quais práticas, a psiquiatria transformou-se no espaço de saber privilegiado para garantir a "defesa da sociedade" 3 de qualquer fator que pudesse representar uma ameaça à ordem, como o crime e a loucura. Ou seja, o momento em que a psiquiatria agrega um tal nível de poder, que passa a transformar-se em uma estratégia de biopolítica das populações.

Loucos e degenerados mostra como a preocupação médico-jurídica com pequenos desvios de conduta, debilidades de caráter e vícios tem seu marco histórico alinhado à teoria da degeneração. E foi essa teoria que permitiu o surgimento do que a autora, como Foucault (2001), chama de psiquiatria ampliada, o alargamento das fronteiras dessa especialidade médica, que passa a integrar a seu rol de intervenções não só os objetos da psiquiatria clássica, de Pinel e Esquirol, mas também as pequenas alterações de comportamento cotidiano.

O recuo histórico nos leva até a segunda metade do século XIX, mais precisamente, 1857, ano de publicação do Traité de dégénérescences physiques, intellectuelles et morales de l'espèce humaine et des causes qui produisent ces variétés maladives, de Benedict August Morel. Segundo a autora, é nesse tratado que se dá início ao processo de ampliação da psiquiatria. A teoria da degeneração de Morel teria criado "um marco explicativo para as doenças mentais no interior do qual desaparecem as barreiras taxativas entre o delírio e as anomalias ou degenerações menores, definidas como desvios físicos ou morais do tipo originário" (p.17).

Para Georges Canguilhem (1991), a tarefa própria da história das ciência é o estudo das 'filiações conceituais'. É essa complexidade de filiações que nos permite transitar entre diferentes espaços de saber. Para analisar como surgiu a psiquiatria ampliada, capaz de antecipar e prevenir os desvios de conduta dos indivíduos desde sua infância, Sandra Caponi precisou analisar a emergência, os usos e as transformações sofridas pelo conceito de degeneração no âmbito do discurso psiquiátrico, passando por diversos momentos históricos. O privilégio dado à história dos conceitos vincula-a ao modo de compreensão da história da ciência, inaugurado por Canguilhem. Segundo a autora, esse privilégio concedido à história conceitual se deve a duas razões: a primeira delas é que a análise dos conceitos nos permite compreender a historicidade e a transformação das teorias científicas; a segunda vem do fato de que os conceitos não conhecem fronteiras epistemológicas (p.173). De forma que o conceito de degeneração não é eminentemente biológico e nem social, encontra-se na fronteira dos estudos clínicos, da estatística, da anatomia cerebral e das ciências sociais.

A história do conceito de degeneração começa a ser traçada no primeiro capítulo, em que a autora aborda o 'tratamento moral', proposto por Philipe Pinel em 1801 e suas diferenças em relação à teoria da degeneração de Benedict Morel. Pinel se negava a reduzir as alienações mentais a explicações materialistas. A conhecida imagem, quase mítica, de Pinel libertando os loucos de suas correntes, simboliza o humanismo moderno. A teoria da degeneração de Morel é herdeira dos estudo de Jean Pierre George Cabanis, que em seu Rapports du physique et du moral de l'homme, publicado em 1802, persegue o objetivo de fundamentar em bases científicas e não metafísicas a ciência do homem. Para ele, existiria uma indissolúvel articulação entre o físico e o moral, possibilitada pelas funções do cérebro. É justamente em Rapports du physique que Sandra Caponi busca as ferramentas que nos auxiliarão durante sua narrativa a compreender como o conceito de degeneração se integra ao saber médico. 
No segundo capítulo, a autora mostra de que modo Cabanis integra o conceito de degeneração, originário da história natural, em particular das teorias climáticas de Buffon, ao campo da medicina, vinculando esse conceito às promessas da anatomopatologia de encontrar explicações em lesões no cérebro para os sofrimentos mentais.

O terceiro capítulo mostra como a teoria da degeneração de Morel cria um marco explicativo para as doenças mentais, oferecendo aos alienistas um fundamento organicista que se refere às lesões cerebrais e à predisposição hereditária. E é nesse momento que ocorre a possibilidade de estender os domínios da psiquiatria para além das fronteiras dos asilos. A aplicação da teoria da degeneração às doenças mentais teria sido a estratégia discursiva que permitiu aos mais variados fatores e condutas ingressar no campo da psiquiatria. O que Foucault (2001) chamou de medicina do não patológico, ou seja, aquela que não pretende somente curar, mas antecipar e prevenir condutas indesejáveis, como a homossexualidade, o alcoolismo e os vícios.

O quarto capítulo trata dos desdobramentos da teoria da degeneração de Morel nos trabalhos de Magnan e seus discípulos em 1893. A partir de pesquisa nos Anais de Higiene e Medicina Legal e nos Anais Médico-Psicológicos, a autora demonstra a permanência do discurso da herança mórbida e da degeneração no campo médico-científico francês, em especial na medicina mental, até a segunda década do século XX.

A teoria da degeneração, particularmente influente na França da metade do século XIX ao início do XX, terá impacto na psiquiatria mundial. Um dos exemplos trabalhados pela autora é o texto, de 1908, do psiquiatra alemão Emil Kraepelin, denominado "Sobre a questão da degeneração". A leitura das obras de Kraepelin, feita por Caponi, nos permite compreender, no quinto capítulo, como o conceito de degeneração reaparece no início da psiquiatria contemporânea. E como se articulam, teórica e conceitualmente, a teoria da degeneração de Morel e a classificação das doenças mentais de Kraepelin.

Grande parte da psiquiatria contemporânea se reconhece e se identifica como 'neokraepeliniana'. É no capítulo sexto, ponto alto da obra, que são analisadas as continuidades e rupturas entre a ampliação de síndromes, proporcionada pela teoria da degeneração da segunda metade do século XIX, e a atual multiplicação de diagnósticos psiquiátricos, representada pelas sucessivas edições do Manual de diagnóstico e estatística de transtornos mentais (DSM).

O livro traz ainda, como um recurso retórico, um post-scriptum que, como a autora explica, não aborda de maneira direta a problemática da degeneração, mas discute uma "encruzilhada teórico-conceitual que parece definir a psiquiatria atual" (p.18). Caponi traz as reflexões de Canguilhem (1993) sobre normalidade e patologia para problematizar o limitado espaço que certos saberes médicos dedicam à compreensão de sofrimentos individuais. A biomedicina contemporânea empenha-se em medir, quantificar, localizar lesões que expliquem desvios de conduta, estados de angústia, ansiedade, pânico ou depressão.

A partir do texto de Canguilhem "O cérebro e o pensamento", de 1993, a autora revisa os pressupostos epistemológicos e éticos que fundamentam a teoria da degeneração e as atuais estratégias da psiquiatria para localizar no cérebro funções morais, abrindo assim uma 'reflexão crítica sobre os axiomas e princípios' das novas ciências do cérebro. 
Essa obra possui um devir, uma clara dimensão ética, de pensar a história como uma ferramenta para nos auxiliar a refletir de outro modo sobre o nosso presente. E quem sabe apontar para um futuro, no qual poderemos lidar melhor com a compreensão dos sofrimentos individuais, em especial no âmbito da biomedicina.

No entanto, neste futuro poderemos também ser colocados, todos, dentro do hospício, como fez o personagem de Machado de Assis, o alienista Simão Bacamarte, em obra publicada em 1882. Aliás, mais uma escolha certeira da autora, é Machado de Assis quem dá o tom da crítica ao assunto que será discutido em cada capítulo, com pequenas epígrafes ditas por seu alienista. Isso ratifica uma vez mais a forte influência que a teoria da degeneração e a classificação de Kraepelin tiveram e têm na psiquiatria mundial, incluído o Brasil da Primeira República, como mostraram Venancio e Russo (2010).

Portanto, trata-se de uma obra que merece ser consultada por pesquisadores do campo da história das ciências, da epistemologia e filosofia da ciência, mas também torna-se importante em especial para quem lida no dia a dia, no campo da saúde, e da saúde pública em especial, com a epidemia dos sofrimentos cotidianos medicalizados, como depressão, ansiedade, angústia, fracasso, excesso de felicidade ou de tristeza.

Termino com uma passagem de O alienista, de Machado de Assis, que introduz também a conclusão do livro de Caponi (p.173): "Nada tenho que ver com a ciência; mas, se tantos homens em que supomos juízo são reclusos por dementes, quem nos afirma que o alienado não é o alienista?" Um exemplo do século XIX para se pensar sobre a saúde mental dos próximos séculos.

\section{NOTAS}

${ }^{1}$ Entre as principais obras do período arqueológico estão: História da loucura na idade clássica ([1961] 1978); O nascimento da clínica ([1963] 2006a); A arqueologia do saber ([1969] 1987).

${ }^{2}$ As principais obras da fase genealógica de Foucault são: Vigiar e punir ([1975] 2000b) e História da sexualidade, 1: a vontade de saber ([1976] 1985).

${ }^{3}$ Título do curso dado por Michel Foucault (2000a) no Collège de France, entre 1975 e 1976.

\section{REFERÊNCIAS}

CANGUILHEM, Georges.

Le cerveau et la pensée. In: Collège international de philosophie. Georges Canguilhem: philosophe, historien des sciences. Paris: Albin Michel. p.1133. 1993.

CANGUILHEM, Georges.

O objeto da história das ciências. In: Carrilho, Manuel Maria (Org.) Epistemologia: posições e críticas. Lisboa: Fundação Calouste Gulbenkian. 1991.

FOUCAULT, Michel.

O nascimento da clínica. Rio de Janeiro: Forense Universitária. 2006a.

FOUCAULT, Michel.

O poder psiquiátrico. São Paulo: Martins Fontes. 2006b.
FOUCAULT, Michel.

Os anormais. São Paulo: Martins Fontes. 2001.

FOUCAULT, Michel.

Em defesa da sociedade: curso no Collège de France (1975-1976). São Paulo: Martins Fontes. 2000a.

FOUCAULT, Michel.

Vigiar e punir: o nascimento da prisão. Rio de Janeiro: Vozes. 2000b.

FOUCAULT, Michel.

A arqueologia do saber. Rio de Janeiro: Forense Universitária. 1987.

FOUCAULT, Michel.

História da sexualidade, 1: a vontade de saber. Rio de Janeiro: Graal. 1985. 
FOUCAULT, Michel.

História da loucura na idade clássica. São Paulo: Perspectiva. 1978.
VENANCIO, Ana Teresa A., Russo, Jane. Classificando diferenças: as categorias demência precoce e esquizofrenia por psiquiatras brasileiros na década de 1920. História, Ciência, Saúde Manguinhos, Rio de Janeiro, v.17, supl.2, p.327324. 2010.

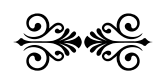

